\title{
Those Outsiders: How Downstream Externalities Affect Public Good Provision
}

\author{
Jason Delaney \\ School of Business Administration \\ Georgia Gwinnett College \\ 1000 University Center Ln. \\ Lawrenceville, GA 30021 \\ jdelaney@ggc.edu \\ Phone: 678-249-9952
}

\author{
Sarah Jacobson \\ Department of Economics \\ Williams College \\ 24 Hopkins Hall Dr. \\ Williamstown, MA 01267 \\ Sarah.A.Jacobson@williams.edu \\ Phone: 413-597-2476
}

Fax: 413-597-4045

December 2013

\begin{abstract}
:
Some policy problems pit one group's interests against another's. One group may determine provision of a project (such as a dam) that benefits group members but hurts others. We introduce a model of such projects. In-group members may contribute to a common fund that benefits them as a public good. Benefits from the project may vary within the group. Provision has negative downstream externalities: contributions hurt agents outside the in-group ("Outsiders"), rendering them anti-social. Many models of social preferences predict that such externalities should reduce provision, although conditional cooperation or a preference for ingroup members may counteract this. We test this model with a lab experiment using Outsiders with whom the in-group members have more and less contact. With homogeneous in-group benefits, the presence of negative downstream externalities reduces contributions by half when they have closer contact with Outsiders but not at all when they have had no contact. We introduce a rotating high-return position that allows subjects to trade favors. In this setting, contributions of non-privileged members diminish slightly when faced with the negative externality given closer contact with Outsiders, and not at all with less contact. Reciprocal giving occurs whether or not Outsiders are present.
\end{abstract}

JEL codes: C91, D01, D62, D71, H41, Q50

Keywords: public bad, public good, externalities, in-group-out-group, social preferences, reciprocity, parochial altruism, social distance 


\section{Introduction}

Decision-making in an environmental setting is special because it often involves externalities, including cases of public goods, and in these cases we expect people's behavior to diverge from the optimum. Sometimes these decisions are rendered more complex when a policy or project creates both winners and losers, and when not everyone has voice in the execution. Many public works projects act as public goods for a set of beneficiaries but impose costs on others. For example, a dam (Richter et al., 2010) may benefit locals but hurt people who live downstream as ecosystems and agricultural systems are degraded; or, as noted in Duflo and Pande (2007), a dam may hurt politically unconnected locals by flooding their lands while it provides water management benefits to politically-connected people who live downstream. Public works to divert water for irrigation or other uses may have serious consequences for other uses, in cases ranging from California's proposed peripheral canal (Jennings, 2012) to diversions of water from the Mekong River in southeast Asia (Winwong, 2008). Many other environmental actions have a similar characteristic. A biomass plant (Foley, 2010) provides local stimulus but pollutes downwind towns. An inefficient ethanol subsidy (Holland et al., 2013) benefits corn state politicians who draft the measure but wastes taxpayer money. In the most troubling cases, the loss to losers outweighs the "public good" gain to winners. Given the power to decide on such a project, will its beneficiaries be sensitive to the harm they cause to others and society as a whole ${ }^{1}$ Additionally, the benefits provided to in-group members by many such projects may vary substantially from person to person; particularly in legislative settings, a series of overall

\footnotetext{
${ }^{1}$ A similar problem arises in valuation studies. If some survey respondents value an environmental asset more than others and they know their high values could cause a tax or fee to be levied on neighbors who value it less, will those respondents shade their reported values down or even state a value of zero to protect their friends?
} 
anti-social projects may each be the pet project of one in-group member. Will that structure see greater or lesser restraint as compared to a homogeneous in-group benefit situation?

We develop a novel model of this scenario and implement that model in a laboratory experiment to study how people react when common project provision creates a large negative externality borne by others. We find that the presence of this negative externality imposes some restraint on contributions in some conditions, but that restraint is quite incomplete and depends on the group incentive structure. When in-group members have no contact with Outsiders, provision continues unabated.

This research question cannot be answered by existing work in the public goods literature (useful surveys of which include Chaudhuri, 2011; Ledyard, 1995). That literature shows that subjects cooperate more than the model of perfectly forward-looking and self-interested agents would suggest, and these results have been used to demonstrate the presence of pro-social preferences such as altruism (e.g., Dawes, 1980) or conditional cooperation (Gächter, 2007), although other motives have been advanced, such as confusion (e.g., Andreoni, 1995a; Ferraro et al., 2003; Houser and Kurzban, 2002). Settings with heterogeneous returns within the group (first studied in Goeree et al., 2002) have further demonstrated the strength of reciprocity as it is leveraged in public goods settings when in-group benefits vary as in some of our scenarios of interest (Jacobson and Petrie, 2013). Reuben and Riedl (2009) use similarly heterogeneous returns to show that "privileged groups" (with a member who has incentive to support the public good) are in some ways ineffective at raising contributions because non-privileged members do not seem to respond to the privileged member's contributions, while Glockner et al.(2011) find that group members respond positively when the privileged member has a relatively high 
incentive but not a dominant strategy to contribute. These results do not demonstrate how subjects' cooperation changes, however, when in-group cooperation is anti-social.

Research on public bads is comparatively limited. A public bad is often treated as the mirror image of a public good: reducing the public bad of pollution, for example, is modeled as providing the public good of pollution abatement. However, the two differ. The Nash equilibrium for selfish actors in a typical public good game is to give nothing, whereas for a public bad game it may involve unboundedly large provision (Shitovitz and Spiegel, 2003). Experimental evidence suggests another difference. The change of a frame from public good provision to public bad prevention causes behavior to be less pro-social (e.g., Andreoni, 1995b; Schwartz-Shea, 1983; Sonnemans et al., 1998). Thus, although this has not been tested before, if agents decide on provision of a project that is a local public good but has global costs that make it a public bad, in-group cooperation could be relatively unhindered by concern for those costs.

When costs are incurred by members of the group of deciding agents, but other members of the group benefit, limited evidence shows that people tend to pursue self-interest. Isaac et al. (2013) use some projects that are overall pro-social and some that are overall anti-social and allow subjects to effectively contribute toward either increasing or decreasing provision; they find that subjects tend to contribute in accordance with their financial interests. Delaney and Jacobson (2013) use a rotating asymmetry, where one group member benefits each period at the expense of the other group members. They too find that subjects' contributions are mostly driven by their own payoffs and they find favor-trading in support of the public bad. Unlike our present study, however, all those affected are in the same group and have decision-making power.

Our study also relies on relevant lessons from studies of heterogeneous returns within and across groups and studies that mix benefits and costs. The intergroup conflict literature indicates 
that damage to other groups can actually increase within-group contributions (Bornstein, 2003; Bornstein and Ben-Yossef, 1994), and this has been attributed to an in-group bias or parochial preference (Baron, 2001). This kind of bias for the in-group can also be seen in the social identity literature, although when agents have little reason to identify with their in-group the extent of this bias seems to vary with the game being played (Chen and Li, 2009). Degrees of sensitivity to or willingness to sacrifice the well-being of those outside the in-group can also be observed in experiments that model firm decision-making (Ellman and Pezanis-Christou, 2010), oligopoly (Engel, 2007), and rent-seeking contests (Abbink et al., 2010).

Our study differs from these in that we study the effect on cooperation of costs that this cooperation will impose on people outside the in-group. The most relevant literature is the small body of experimental work on downstream externalities. Schwartz-Shea and Simmons (1990, 1991) find that when playing a Prisoner's Dilemma game in which cooperation reduces contributions to a charity, subjects cooperate with each other more when they can communicate (which may increase in-group identification) and when the downstream charity is considered less deserving. However, they do not measure the effect of the presence of the outside entity and we feel the use of other ordinary subjects as outside entities is more appropriate for our research question. In very related research, Engel and Rockenbach (2011) implement a game in which subjects contribute to a local public good in the presence of "bystanders," who are people outside of the deciding in-group. They use treatments in which the common project has positive, negative, and zero downstream externality on the bystanders, but in all cases the project is overall pro-social. The presence of bystanders reduced provision in all cases except when endowments ensured that the in-group members could not earn less than the bystanders. The authors explain the results as a combination of inequity aversion and conditional cooperation. 
Our study differs in that we focus on projects that are overall anti-social, we use two different kinds of bystanders (with different results in each case), and we also study heterogeneous values within the in-group. Inequity aversion would also play out rather differently in our setting: as we describe later, inequity aversion would generally reduce contributions in our design.

The remainder of the paper proceeds as follows. In the next section, we lay out a model of projects with this kind of heterogeneous benefit. We then present our experimental design. The following section presents our results. The final section concludes.

\section{Projects with Heterogeneous Benefits and Costs}

We model a scenario in which some number $N_{D}$ of agents with deciding power ("ingroup members") choose how much to contribute to a common fund. The common fund acts as a linear public good for in-group members. In each round $t$, each in-group member $i$ has

endowment $z$ tokens and chooses amount $g_{i t}$ to contribute to the common fund. Each token he or anyone else contributes earns him $b_{i t}$. This rate may vary across subjects and rounds. The rest of his endowment yields him a private return of $a$. His earnings are given by equation 1 .

$$
\pi_{i t}=a\left(z-g_{i t}\right)+b_{i t} \sum_{j=1 \ldots N_{D}} g_{j t}
$$

Since this is a public good within the group, the social optimum is for everyone to

contribute fully $\left(\sum_{j=1 \ldots N_{D}} b_{j t}>a\right)$ but there is an individual incentive to free ride for at least some agents $\left(a>b_{i t}\right)$.

In addition to the in-group members, other agents are affected by the project. Some number $N_{O}$ are "Outsiders:" agents who are not members of the in-group and therefore have no 
deciding power, but who are hurt an amount $c<0$ for every unit of project provision. An agent $i$ who is an Outsider in round $t$ earns profit given in equation 2.

$$
\pi_{i t}=c \sum_{j=1 \ldots N_{D}} g_{j t}
$$

Since $c$ is negative, the Outsider earns a negative return from common fund contributions. In the scenario of interest, project provision is overall anti-social:

$\sum_{j=1 \ldots N_{D}} b_{j t}+N_{O} c<0$. The Outsiders' losses outweigh the gains of the in-group members so that the social optimum is for there to be no project provision.

For some projects, all in-group members have the same returns from the common project: $b_{i t}=b \forall i=1 \ldots N_{D}$. In this homogeneous return case, the Nash equilibrium when each in-group member is only interested in his own payoff (that is, $\frac{\partial u_{i}}{\partial \pi_{j}}=0, \forall j \neq i$ ), is rational, and knows that all group members are rational and self-interested is to contribute nothing to the common fund. If in-group members are altruistic, the prediction is less clear. If that altruism is parochial in that it privileges in-group members over Outsiders $\left(\frac{\partial u_{i}}{\partial \pi_{j}}>\frac{\partial u_{i}}{\partial \pi_{k}}\right.$ and $\frac{\partial u_{i}}{\partial \pi_{j}}>0$ for in-group members $j$ and Outsiders $k$ ), in-group members may contribute a positive amount. This is particularly true if they actively dislike Outsiders $\left(\frac{\partial u_{i}}{\partial \pi_{k}}<0\right)$. If in-group members are egalitarian altruists in that they are equally concerned with all other agents affected by their actions $\left(\frac{\partial u_{i}}{\partial \pi_{j}}=\frac{\partial u_{i}}{\partial \pi_{k}}>0\right)$, they should contribute nothing. This game thus aligns the actions of free-riders and egalitarian altruists, but not parochial altruists. 
Agents may also engage in conditional cooperation: they may contribute positive amounts in response to other agents' past contributions. This group-level reciprocation is unfocused since agents cannot directly reward specific in-group members for past cooperation. However, conditional cooperation has been shown to be important in public good games (Gächter, 2007). Importantly, Outsiders can do no act to earn an in-group member's reciprocal kindness, nor can they reciprocate any kindness. Conditional cooperation can work to increase contributions at the expense of Outsiders.

What other types of preferences could affect contributions? First, if in-group members are inequity-averse, their decisions depend on their beliefs about Outsiders' baseline payoff. Ingroup members who are inequity-averse but have no other social preferences (e.g., no altruism) should, if they believe that Outsiders have baseline payoffs less than or equal to what an in-group member would earn with no contribution, contribute nothing because neither self-interest nor inequity-aversion motivate contributions. If they believe that Outsiders' have larger baseline payoffs, this could induce them to contribute up to the point at which the "price" of contributing (through sacrifice of own payoff) is balanced by utility gains from a decrease in disadvantageous inequality. Second, in-group members who have moderate preferences for efficiency may be sensitive to the overall group payoff. That is, the more negative the overall group payoff, the more restraint will be shown by in-group members who have preferences for efficiency.

For some projects, there are members of the in-group who have a greater stake in provision than others. For example, a farmer may particularly benefit from a local dam. There may be a series of projects that each benefits a group member; for example, a set of legislators may each bring forward a wasteful amendment that mainly benefits his/her constituency. We model this increased interest with a higher return from the common fund. We call these agents 
"Stakeholders," and they are identified by index Stake $_{t} \in\left\{1, \ldots, N_{D}\right\}$. The Stakeholder position may be held by different in-group members in different rounds as different projects have different beneficiaries. A case of interest is the case of a "privileged group" (following Olson, $1965)$ where the Stakeholder has a dominant strategy to contribute $\left(b_{\text {Stake }}>a\right)$, even though all other subjects still have incentive to free ride $\left(b_{i t}=b<a\right)$. The in-group social optimum is full contributions by all in-group members, but Outsiders' pain still outweighs in-group members' gains, so the project is still overall anti-social.

In this heterogeneous-return case, efficiency-seeking and egalitarian altruism should still drive in-group members to not contribute, while parochial altruism and conditional cooperation could still drive in-group members to contribute. What role could inequity aversion play? If we consider the entire game with many rotations of the Stakeholder position through all in-group members, the Stakeholder role will not affect payoff equity, so inequity aversion should have the same motivating effects as in the homogeneous returns case. ${ }^{2}$ Each agent's higher overall earnings (higher because of high Stakeholder returns) changes the difference between in-group earnings and Outsider earnings: it decreases disadvantageous inequity if Outsiders are believed to earn more, and it increases advantageous inequity if Outsiders are believed to earn less. Both of these would tend to make in-group members contribute less to the common fund.

When projects have heterogeneous returns, in-group members also have a more precise way of practicing reciprocity. ${ }^{3}$ The heterogeneous return case is interesting both because it

\footnotetext{
${ }^{2}$ Since the Stakeholder position rotates through all group members, returns to each group member across all rounds should be roughly symmetric. However, if agents are very myopic so that they focus only on the current interaction, inequity aversion could make them choose contribution levels that reduce current-round payoff inequality between the Stakeholder and non-Stakeholders.

${ }^{3}$ The reciprocity we focus on consists of responses to acts the agent has observed another agent taking that have kind or unkind consequences toward this agent, as in Cox et al. (2008) and Wilson (2008). Rabin (1993) considers normal form games. Here, something like reciprocity depends on a belief about how kind another agent is being in a simultaneous game, and this allows reciprocity to occur without such a sequence. However, Rabin's
} 
models scenarios of interest from outside the lab and because it allows us to study reciprocity more carefully in this setting. Rather than simply engaging in group-level conditional cooperation, in-group members can choose to target each other with rewards for past "generous" behavior. Imagine that Joe and Fred are in a group together and they have no preference with regard to Outsiders' payoffs. If Joe is the Stakeholder in round 1, he will contribute fully to the common fund and he will want Fred to contribute as well. If Fred contributes in round 1, then when Fred is Stakeholder in round 2, Joe may reward Fred by contributing a large amount, since this will increase Fred's earnings. If Fred gave little in round 1, Joe may withhold that reward.

This favor-trading could happen because in-group members are reciprocators (i.e. their preferences over others' outcomes depend on others' past actions). However, selfish agents may strategically mimic reciprocators if they believe they are facing reciprocators or if rationality or foresight is limited. Per Sobel's (2005) terminology, this would be instrumental reciprocity, whereas intrinsic reciprocity depends on other-regarding preferences. Both may be important in this setting. Again, Outsiders can do nothing to inspire either a reciprocation or a strategic conditional contribution. In summary, in the heterogeneous return case, conditional cooperation in response to group-level contributions, intrinsic reciprocity, and instrumental reciprocity may all drive positive in-group contributions in the presence of Outsiders.

In what other ways should a heterogeneous in-group behave differently from a homogeneous in-group? This higher reward associated with the Stakeholder position makes ingroup members richer than they would be in the homogeneous return case. If marginal utility diminishes in wealth, agents in a heterogeneous return setting may be more willing to sacrifice their own payoff to benefit others; if this feeling is indiscriminate or favors Outsiders, this could

theory is of Nash equilibria in which beliefs must be correct, so even this theory is not devoid of dependence on the other agent's action. We leave aside ideas of reciprocity that do not depend on a history of observed actions, because the existing experimental literature focuses on reciprocity based on history and because we cannot observe beliefs. 
decrease contributions, but if it favors in-group members it could increase contributions.

Alternately, the promise of a large reward from in-group cooperation could cause agents to contribute more since the costs of restraint (the benefits of cooperation) are higher.

\section{Experiment Design}

The experiment design is based on the model described above. In each treatment, subjects make decisions in each of eight rounds: how many tokens to contribute to a Group Fund that represents a linear local public good. We implement six treatments. The three externality conditions are No-Outsiders, Local Outsiders (in which each group includes Outsiders who are members of a different group), and Remote Outsiders (in which each group is associated with Outsiders who are in a separate room and make no decisions). These are interacted with 2 payoff structures, Homogeneous Return and Heterogeneous Return, for six treatments in total. All six treatments use in-group sizes of $N_{D}=4$, and, where applicable, use $N_{O}=2$ Outsiders per ingroup. In each, in-group members have an endowment of $z=20$ tokens per round. In each round each must allocate his tokens between his private fund, which has a per-token return of $a=2$ cents to him only, and the common fund with returns described below.

In the Homogeneous Return treatments, the common fund return is $b=1$ cent per token for all in-group members. The common fund acts as a public good for the in-group. Each token contributed to the common fund creates four cents of in-group profit, whereas it would only generate two cents if it were invested privately, for a net social benefit of two cents. Each ingroup member has an incentive to free-ride because he earns more from a token in his private fund as compared to the common fund. When Outsiders are present, their returns from common fund contributions are $c=-3$ cents per token. In this case, the common fund acts as a public bad 
overall: each token invested in the common fund generates two cents of net profit for the ingroup and six cents of loss for the Outsiders, for a net social cost of four cents.

In the Heterogeneous Return treatments, a Stakeholder position rotates through members of the in-group in an observable and predictable fashion so that each decider is Stakeholder twice. The Stakeholder's common fund return is $b_{\text {stake }}=3$ and the return for Non-Stakeholder ingroup members is $b=1$. In this case, a token contributed to the common fund earns six cents for the group at an opportunity cost of two cents, for a net social benefit of four cents. With Outsiders, who again earn $c=-3$ from the common fund, the in-group social benefit of four cents is again reduced by the six cents of loss to Outsiders for a net social loss of two cents.

The net social cost of a contribution is always two cents greater in the Homogeneous Return treatments than in the Heterogeneous Return case; put another way, the social cost of contribution in both treatments is reduced by the same absolute amount (six cents per token) when Outsiders are added, but this means the relative change in social cost differs ${ }^{4}$ and so does the total social value of a token contributed. To implement heterogeneous returns, it was necessary to change either the social return to Non-Stakeholders or the private return from the private fund or both. Were the private return reduced to hold constant the net social return, it is likely that altruists, reciprocators, and inequity-averse people would react in complex ways. Instead, the private return is held constant, and the social return changes across treatments. This change in the distribution of payoffs complicates direct comparisons of contribution levels across Homogeneous and Heterogeneous Return treatments.

\footnotetext{
${ }^{4}$ The same absolute change in social cost corresponds to a smaller relative change in social cost in the Heterogeneous Returns treatment as compared to the Homogeneous Returns treatment. If agents respond to relative rather than absolute change in social cost, the reduction in contributions when Outsiders are added may be smaller in the Heterogeneous than the Homogeneous Returns case.
} 
In the Local Outsider treatments, Outsiders for each in-group are randomly selected from other in-groups. No subject knows whether he has been chosen as an Outsider until after the experiment is over and total experimental earnings are revealed. This has an element of realism, because in many downstream externality settings outside the lab a group is simultaneously "upstream" from one perspective and "downstream" from another. No mutual reciprocation is possible between Outsiders and in-group members for the following reasons. First, no one knows whether he is an Outsider until the end of the experiment. Second, no one knows how other groups are behaving and therefore how he is being treated if he is an Outsider until the experiment is over. Finally, Outsider-to-group pairings are not reciprocal: if Outsiders attached to Group 1 are members of Group 2, it is not the case that the Outsiders attached to Group 2 are members of Group 1. Still, the potential for role reversal may reduce or increase restraint on the part of deciders (see, e.g., Burks et al., 2003). On the other hand, since Outsiders belong to other groups, subjects could see the situation as one of inter-group competition, although we do not frame it this way. This could increase in-group cooperation.

In the Remote Outsider treatments, Outsiders for each in-group are randomly selected from a set of experimental subjects in a different room who participate in a brief survey task for which they receive a fixed payment. Contributions made by matched members of the in-groups in the other room reduce this payment.

The Local Outsider treatment is analogous to a setting in which a set of communities are clustered together and each may have industrial facilities or power plants that provide net benefits within the community but impose environmental externalities on neighboring communities. The Remote Outsider treatment models settings in which the flow of externalities is strongly directional: for example, such a setting occurs when a dam-building community is 
upstream from another community, or when an empowered group of legislators or lobbyists takes action (as in the case of inefficient ethanol subsidies).

The subject interface is computerized and was programmed in z-Tree (Fischbacher, 2007). At the start of the experiment, subjects read general instructions. ${ }^{5}$ They are told that they will make decisions in two sets of eight rounds each (i.e., two treatments) and that they will be randomly assigned into groups which will remain fixed for each set of rounds, but that groups will be different for the first and second sets of rounds. Subjects are not told the exact nature of the decisions they will make in each treatment until the treatment-specific instructions are read. Each subject participates in either two Homogeneous Return treatments (with and without one type of Outsiders) or two Heterogeneous Return treatments.

The first treatment begins with instructions that explain the payoff structure for that treatment. The subjects play through all of the rounds for the treatment. When the first treatment is over, the groups are randomly re-matched. The second treatment proceeds similarly, with treatment-specific instructions read first. After both treatments, subjects complete a questionnaire and are paid anonymously. Subjects' total earnings are the sum of their earnings in each treatment, which in turn are the sum of earnings in each round. The experiment is "doubleanonymous" in the sense that subjects do not know which other subjects they are interacting with and the experimenters do not know which subject made which set of decisions.

In addition to the payment for their decisions, all in-group subjects receive a fixed payment of $\$ 16$. This increases subjects' worst-case earnings so no subject can earn a negative amount even with large losses for Local Outsiders.

In the software for each treatment, subjects see a decision screen and then, after making a decision, a review screen for each round. In both the decision and review screens, the central

\footnotetext{
${ }^{5}$ Instructions are available on the corresponding author's website: http://econ.williams.edu/people/saj2
} 
feature is the contribution table. This table contains a row for each round in the treatment.

Columns contain information on the subject's contribution and the contributions of others in his group, the group's total contributions, and the subject's own earnings. Information is filled into this table after the decision stage of each round and remains visible for the rest of the treatment. In the Outsider treatments, the presence of Outsiders (referred to in the software and instructions as "Outside People") and the return to Outsiders from the common fund are indicated in the header and at the footer of the screen.

Figure 1 shows the decision screen for the Heterogeneous Return treatment with Outsiders. In the Heterogeneous Return treatments, Stakeholder assignments are common knowledge. This feature lets subjects, if they so choose, target a benefactor for a reward in the form of high contribution when that benefactor is Stakeholder. To return to our example, if Joe is subject A and Frank is B, Joe can see how much Frank contributed in Round 1 when Joe was the Stakeholder. Joe can reward Frank with a large contribution when Frank is Stakeholder in Round 2, or Joe may withhold that reward if he deems Frank's contribution stingy. ${ }^{6}$

\section{FIGURE 1 GOES ABOUT HERE}

\section{Results}

The experiment was run at the Experimental Economics Center (ExCEN) at Georgia State University in March 2011 and January 2013. Overall, 236 subjects participated in twelve sessions. Eight sessions featured the Local Outsider condition: four sessions each of the Homogeneous Return case (with 20 subjects per session, for 80 subjects total) and the Heterogeneous Return case (three sessions with 20 subjects and one with 16 subjects, for 76

\footnotetext{
${ }^{6}$ While targeted reciprocity is made possible by the payoff structure, the instructions and software do not explicitly state this. Thus any reciprocity we see requires subjects to independently discover this possibility.
} 
subjects total). Four sessions featured the Remote Outsider condition, two with Homogeneous Return and two with Heterogeneous return (with 20 subjects per session, for 80 subjects total). ${ }^{7}$ All subjects experienced a treatment with Outsiders and a treatment without Outsiders. Half of the sessions of each type ran the Outsider treatment first and half second. We report results pooled from both orders. ${ }^{8}$

\section{Descriptive Results}

Of the 236 subjects, $133(56.36 \%)$ were female and the average age was 20.61. On average, subjects earned \$23.31 in Homogeneous Return sessions (payments ranged from \$14.38 to $\$ 28.07$ ) and $\$ 25.59$ in Heterogeneous Return sessions (with a range of $\$ 13.48$ to $\$ 31.57$ ).

Figure 2 shows the trend of average contributions by treatment and by role. Figure $2 \mathrm{a}$ shows that in the Homogeneous Return treatments, contributions compare well with other public good games. In Ledyard's (1995) survey of public goods game results, first period contributions range from $31-68 \%$ of endowment and final period contributions range from $9-19 \%$ of endowment. In the Homogeneous Return treatments, first period contributions average 45.38\% of endowment and final period contributions average $30.25 \%$ of endowment when there are no Outsiders. The addition of Outsiders reduces first period average contributions to $41.29 \%$ and final period contributions to $20.38 \%$. The average within-period contribution when Outsiders are present is generally below the average within-period contribution without Outsiders.

\footnotetext{
${ }^{7}$ In addition, 40 subjects participated as Outsiders in the Remote Outsider treatments, but made no decisions and produced no data for this study.

${ }^{8}$ A subject's contributions to the common fund were less in the subject's second treatment for several treatments and roles. Results if data from the second treatment are excluded are the same as the results reported here except: the difference between contributions in the Homogeneous Return Local and Remote Outsider treatments (compare to Table 1) ceases to be significant $(p=0.142)$, reciprocal giving in the Local Outsider treatment (compare to Table 3 ) ceases to be significant $(p=0.155)$, and the estimates of $\beta_{3}$ and $\beta_{4}$ in Equation 3 and Table 2 are rendered marginally significant ( $p$-value $=0.109$ and $p$-value $=0.095$, respectively). The results in Table 4 are qualitatively similar except that the estimates of the coefficient on previous Stakeholder contributions are smaller and much noisier in the first-treatment-only analysis. As subjects were not explicitly made aware of the opportunity for reciprocity, it seems that it took some time for subjects to discover the potential for reciprocity.
} 


\section{FIGURE 2 GOES ABOUT HERE}

Figure $2 \mathrm{~b}$ shows that in the Heterogeneous Return treatment, Stakeholder contributions are high — nearly $100 \%$ of endowment — whether Outsiders are present or not, although contributions when Outsiders are present are generally below contributions without Outsiders. Figure 2c shows that Non-Stakeholder contributions are similar in level to contributions in the Homogeneous Return treatment. For Non-Stakeholders, the introduction of Outsiders has little effect on contributions. In Jacobson and Petrie (2013), with a similar asymmetric payoff setup, Stakeholders contributed close to the same amount they do here in the No-Outsiders case (9597\% of endowment), while Non-Stakeholders gave slightly less than they do here (33-38\%), and both roles show trends similar to the trends shown here. Non-Stakeholder contributions can also be compared to contributions by subjects with low marginal per capita returns in similar treatments of other heterogeneous return experiments: such subjects gave $20 \%$ on average in Goeree et al. (2002), 22.5\% in Reuben and Riedl (2009), and 18\% in Glöckner et al. (2011).

\section{The Outsider Effect}

In Table 1, we verify these trends and differences by comparing mean contributions across treatments and roles. The addition of Outsiders does restrain contributions to the common fund quite significantly, but it never drives them to zero and sometimes has no effect. In the Homogeneous Return treatment, subjects give $47.30 \%$ when there are no Outsiders present as compared to $24.91 \%$ when Local Outsiders are present, for a reduction of $47 \%$, which is significant at the $1 \%$ level. When Remote Outsiders are present, contributions dip only to $43.39 \%$, for a statistically insignificant reduction of $8 \%$. In the Heterogeneous Return treatment, Stakeholders reduce contributions by $11 \%$ when Local Outsiders (significant at the $5 \%$ level) and 9\% when Remote Outsiders (not significant) are added. Non-Stakeholders increase 
contributions by $2 \%$ with Local Outsiders, but decrease contributions by $11 \%$ with the introduction of Remote Outsiders, and neither of these changes is statistically significant. ${ }^{9}$

\section{TABLE 1 GOES ABOUT HERE}

When Outsiders exist, the common project is anti-social because costs to Outsiders outweigh local public good benefits to in-group members. We find it remarkable that even though we made no effort at in-group identification, subjects sacrifice self-interest to contribute at significant levels to such an anti-social endeavor. This could be explained by a parochial altruism that favors in-group members and perhaps the fact that kindness to an Outsider is effectively thankless while kindness to in-group members may be reciprocated. ${ }^{10}$

Is the Outsider-induced reduction in contributions meaningfully smaller in the Heterogeneous Non-Stakeholder case as compared to the Homogeneous Return case? This is a nontrivial question to answer since the incentive structures differ across the treatments: in both cases introducing Outsiders increases the social cost of contributions by 6 cents, but in-group returns in the Heterogeneous Return treatment are larger than in the Homogeneous Return treatment because of the Stakeholder's high return. As we argue in the Experiment Design section, this difference was less disruptive than allowing other returns to change. We test for a difference in the absolute ${ }^{11}$ changes in contributions when Outsiders are added between the Homogeneous and Heterogeneous Return treatments. Because we have repeated observations for individuals, we can use a within-subject test of a difference in Outsider-induced reductions. (The averages for the No-Outsider condition used in these tests differ slightly from those reported in

\footnotetext{
${ }^{9}$ Table 1 shows tests using the group as the unit of observation. If subject-level averages are used instead, all results persist.

${ }^{10}$ It is also possible that subjects following a "majority rule" ethic will favor in-group members since there are four total members of the in-group and only two Outsiders.

${ }^{11}$ Since the magnitude of Heterogeneous Return Non-Stakeholder No-Outsider contributions is generally smaller than Homogeneous Return No-Outsider contributions, a relative drop in contributions would cause the Heterogeneous Return drop to look slightly larger than it would look using the absolute drop.
} 
Table 1 since Table 1 pools No-Outsider data from Local and Remote Outsider sessions.) Subjects reduced their contributions by $22.89 \%$ of their endowment with the introduction of Local Outsiders under the Homogeneous Return treatment, while Non-Stakeholders only reduced their contributions by $2.84 \%$ of their endowments in the analogous case under the Heterogeneous Return treatment, and so it appears that the effect of Local Outsiders depends on the symmetry of the payoff structure (Wilcoxon rank-sum $p$-value $<0.001$ ). With the introduction of Remote Outsiders, those in the Homogeneous Return treatment reduced their contributions by $2.88 \%$ of their endowments, while Non-Stakeholders in the Heterogeneous Return actually increased their contributions by $2.44 \%$ of their endowments, and this difference is not significant $(p=0.341)$.

These within-subject tests assume independence across subjects embedded in groups, but there is good reason to believe that contributions might be correlated. To account for this, we can look at how average group contribution levels vary across treatments.

Let $G_{i}$ be the average contribution level for group $i$ and let the superscripts $O L$ indicate the presence of Local Outsiders and $O R$ indicate the presence of Remote Outsiders. Let the superscript Hetero refer to Heterogeneous Returns. Since treatments are exogenously imposed, we can regress contributions on treatment dummies to test for a differential change in contributions without fear of omitted-variable bias. Defining dummies for each treatment (leaving the No Outsider, Homogeneous Return as the omitted category), we can set up the regression model in equation 3.

$$
G=\beta_{0}+\beta_{1} d^{O L}+\beta_{2} d^{\text {OR }}+\beta_{3} d^{\text {Hetero }}+\beta_{4} d^{\text {OL,Hetero }}+\beta_{5} d^{\text {OR,Hetero }}+\varepsilon
$$

If there is no difference in the contribution reduction that comes when Outsiders are added to the Homogeneous Return treatment as compared to the behavior of Non-Stakeholders 
in the Heterogeneous Return treatment, it should be true that $\beta_{4}=0$ and $\beta_{5}=0$ for Local and Remote Outsiders, respectively. Since Stakeholders have an incentive to contribute fully and generally do, we compare the Outsider-induced drop in average Non-Stakeholder contributions for the Heterogeneous Return case to that for the Homogeneous Return case.

Results are in Table 2. First, the addition of either kind of Outsider has no net effect on contributions in the Heterogeneous return treatment: the sum of the Outsider treatment dummy and the relevant interaction term is not significantly different from zero $(p=0.916$ for Local, $p=$ 0.455 for Remote), echoing the result from Table 1 . Next, the Outsider-induced drop is significant for Local Outsiders $(p=0.003)$, but insignificant with Remote Outsiders $(p=0.990)$. The coefficient on the Local Outsider-Heterogeneous Return interaction is different from that on the Remote Outsider-Heterogeneous Return interaction $(p=0.005)$. Thus we conclude that the presence of Local Outsiders causes a greater drop in contributions in the Homogeneous Return treatment than in the Heterogeneous Return treatment, while there is no difference in the effect of Remote Outsiders across Homogeneous and Heterogeneous Return treatments.

\section{TABLE 2 GOES ABOUT HERE}

The effect of adding Outsiders to groups in this setting can be compared to the effect of adding "bystanders" in Engel and Rockenbach (2011). As previously noted, they find that bystanders reduce provision whenever in-group members risk "falling behind" bystanders in earnings, and attribute behavior to inequity aversion and conditional cooperation. In our study, the effect of inequity aversion in the Local Outsider treatment depends on subjects' expectations about whether they will be Outsider and about how Outsiders will generally be treated, but in the Remote Outsider treatment, inequity aversion should drive contributions down. Conditional 
cooperation may be important, and therefore we look to the Heterogeneous Return treatment for evidence of reciprocal behavior.

\section{Reciprocal Behavior}

In-group members' tendency to continue contributing to the local public good even when Outsiders' pain makes the project overall anti-social may relate, among other things, to some form of reciprocal behavior with regard to in-group members. This is particularly compelling since the reduction in in-group contributions is smaller in the Heterogeneous Return case than in the Homogeneous Return case. In fact, we can look more closely for reciprocal giving because the Heterogeneous Return treatment is designed specifically to allow subjects to selectively reward other subjects if they so choose. The rotating role of the Stakeholder yields a very high return from the common fund, and all contributions and Stakeholder timing are common knowledge. As noted earlier, subjects who wish to engage in costly reciprocation can contribute as Non-Stakeholder when the current Stakeholder is someone who has been kind in the past. ${ }^{12}$

Thus, evidence of favor-trading can be found in Non-Stakeholder contributions in the Heterogeneous Return treatment. For each subject, we generate two measures of his NonStakeholder contributions. First, we see how much he contributed to the common fund in rounds in which the current Stakeholder had previously been nice to him; then we see how much he contributed in rounds in which the current Stakeholder had previously been mean to him. We measure "niceness" for this purpose by looking at the current Stakeholder's past contributions. Any given subject will naturally be particularly concerned with contributions made in past rounds in which he himself was Stakeholder. A current Stakeholder may therefore be considered

\footnotetext{
${ }^{12}$ A simultaneous-game concept of reciprocity as in Rabin (1993) may allow subjects to react not only to other group members' past actions but also to a belief about their current actions. However, in our setting beliefs are most likely formed based on past observed behavior. Also, the reciprocal acts we focus on are fundamentally sequential, since they involve rewarding a current Stakeholder for what he did when you were Stakeholder.
} 
nice if he contributed a large amount when this subject was previously Stakeholder. A current Stakeholder is mean if he did not contribute much when this subject was previously Stakeholder. A subject is behaving reciprocally—-trading favors - if he gives more when the current Stakeholder is a previous benefactor than when it is a previous malefactor.

Table 3 presents the analysis of these measures. The threshold for past behavior of a current Stakeholder to be considered "nice" or "mean" is an endogenous threshold: the cumulative average non-Stakeholder contribution of all other members of the group (excluding both the subject being analyzed and the current Stakeholder). ${ }^{13}$ In all treatments, subjects give significantly more to a previously kind Stakeholder than to a previously unkind Stakeholder. ${ }^{14}$ These tests reduce the sample being analyzed, however, and thus the power of the test. We can only look at the rounds in which a subject is Non-Stakeholder after he has been Stakeholder at least once (which will be 3-6 rounds). In those remaining rounds some subjects don't face both a nice and a mean Stakeholder.

\section{TABLE 3 GOES ABOUT HERE}

The non-parametric tests reported in Table 3 only address unconditional mean levels of contribution, and then only for a sub-sample of our observations. To further study favor-trading, we consider a parametric model of Non-Stakeholder contributions in the Heterogeneous Returns treatment as a function of Stakeholder past generosity with appropriate controls.

We let $g_{i t}^{N S}$ be the Non-Stakeholder contribution for subject $i$ in period $t$, and we index the round $t$ Stakeholder as subject $j$. We define a sequence of favor contributions to $i$ from $j\left(f_{i j s}\right)$

\footnotetext{
${ }^{13}$ Results are qualitatively similar with other thresholds, including the cumulative median non-Stakeholder contribution of the group (including own contributions), 50\% of endowment, and many other levels, though they are not significant for all thresholds.

${ }^{14}$ If we define the level of reciprocity as the difference between what a subject gives to a nice versus a mean Stakeholder, the level of reciprocity does not differ detectably between any treatments (No-Outsider versus Local Outsider paired Wilcoxon signed-rank $p=0.238$, No-Outsider versus Remote Outsider paired Wilcoxon signed-rank $p=0.979$, Local Outsider versus Remote Outsider unpaired Wilcoxon rank-sum $p=0.851$ ).
} 
as only those Non-Stakeholder contributions of $j$ in past rounds $s$ in which $i$ was Stakeholder. Then we can define $j$ 's average favor contribution to $i$ (cumulative as of round $t$ ) as $\bar{f}_{i j t}$, the average of all of $j$ 's contributions in $i$ 's past Stakeholder rounds. The coefficient on this variable can be interpreted as subjects' responsiveness to past generosity of in-group members.

Since group contributions may be correlated, we control for past contributions by the rest of the group. For subject $i$ in round $t$, we define $\bar{g}_{-i t}^{N S}$ as the cumulative-to-round- $t$ average of Non-Stakeholder contributions in past rounds (excluding subject $i$ 's contributions).

We also control for a linear time trend $t$ (i.e., the round number). We represent these three variables of interest $\left(\bar{f}_{i j t}, \bar{g}_{-i t}^{N S}\right.$, and $\left.t\right)$ as a vector of observed variables $\boldsymbol{X}$. Dummy $d^{O R}$ indicates whether the current treatment is a Remote Outsider treatment, and $d^{O L}$ indicates that it is a Local Outsider treatment. Finally, we allow for unobserved individual effects $u_{i}$. We consider both a fixed-effects model, which provides consistent coefficient estimates, and a random-effects model, which provides efficient but potentially biased estimates. A Hausman test indicates that the random-effects model may provide inconsistent parameter estimates $(p=0.088)$. We thus present parameter estimates for both panel fixed-effects regressions and the corresponding random-effects regressions in Table 4 for comparison. Results discussed in the paragraphs that follow use coefficients from the more conservative fixed-effects model, although results are similar using the random-effects coefficients. We consider two primary sets of independent variables. Specification 1 allows for full interaction effects across treatments as specified in equation 4. (Specification 3 presents the corresponding random-effects model.)

$g_{i t}^{N S}=\beta_{0}+\beta_{1} \mathbf{X}_{i t}+\beta_{2} d_{i}^{O R}+\beta_{3}\left(d_{i}^{O R} \mathbf{X}_{i t}\right)+\beta_{4} d_{i}^{O L}+\beta_{5}\left(d_{i}^{O L} \mathbf{X}_{i t}\right)+u_{i}+\varepsilon_{i t}$ 
With this model, if the relationship between Stakeholder past contribution $\left(\bar{f}_{i j t}\right)$ and this subject's current Non-Stakeholder contribution is significant and positive, this is evidence of reciprocal giving, not simply conditional cooperation within a cooperative group. This represents how much more a subject gives to a previously-kinder Stakeholder, holding constant average group cooperation and treatment. This relationship is described by the sum of the coefficient on the Stakeholder past contribution and the interaction between Stakeholder past contribution and the relevant treatment dummy.

\section{TABLE 4 GOES ABOUT HERE}

Testing for reciprocity (by seeing whether the sum of the coefficient on $\bar{f}_{i j t}$ and the coefficient on the treatment interaction term is significantly positive) in the No-Outsider treatment, we see that there is significant favor-trading $(p<0.001)$. We also see significant favor-trading in the Local Outsider treatment $(p=0.002)$ but none in the case of Remote Outsiders $(p=0.445)$. Recall that in Table 3 we found significant favor-trading in the NoOutsider and both Outsider treatments.

This full model may not be the appropriate specification, as it is unclear whether the interaction terms add sufficient explanatory power to justify their inclusion in the model. In a test of the linear restriction that all the coefficients on the interaction terms are equal to zero, we cannot reject the null $(p=0.814)$, implying that we should consider a reduced model without treatment interaction terms.

Specification 2 in Table 4 therefore omits the interaction terms (Specification 4 presents the corresponding random-effects model, and again a Hausman test weakly recommends the fixed-effects model: $p$-value $=0.094)$. The reduced model allows for more precise estimation of the effects of previous Stakeholder contributions. The results show that a Stakeholder receives, 
on average, 0.912 tokens for every token he has contributed to others (this is significantly different from zero: $p<0.001)$. The net private cost of contributing a token when NonStakeholder is 1 cent, while Stakeholders earn 3 cents from each token donated other subjects. The reciprocity-fueled net return to a token contributed by a Non-Stakeholder is thus $3 \times 0.912-1=1.736$ cents - that is, reciprocity makes a Non-Stakeholder contribution profitable on average, although the variation is sufficiently large to make this a risky proposition.

\section{Conclusion}

Many policy directives and institutional designs seek to address simple public goods problems: pollution that hurts everyone or exploitation of a commonly-owned resource. However, there is less literature studying cases in which a project or resource acts as a public good to one group of people while actively hurting others and ultimately social welfare. Such scenarios are widespread and potentially quite problematic. Downstream externalities can hurt overall efficiency and create dramatic distributional issues. Political squabbling can result, as in the case of Farm Bill provisions that provide benefits to a group but hurt others. Intergroup or even international conflict can also arise, as in the case of dams being built on the Mekong River. It is important to understand how people behave and express their preferences in these scenarios so that efficient policy can be developed for these more complicated situations.

We present an experiment that investigates the actions of agents with deciding power over provision of projects with just such mixed social benefits and costs. We find that while a downstream externality does reduce agents' effort at providing a locally-beneficial project, these contributions are not reduced to zero. Further, when contact with those being harmed is decreased, those deciding exhibit no restraint at all. 
This limited restraint is remarkable. Cooperation in public goods settings is often viewed as a pro-social or altruistic act, but in-group members are cooperating here in an anti-social way. This may demonstrate a parochial form of altruism that privileges in-group members over those outside the in-group. This explanation seems particularly compelling since level of contact seems to mediate the Outsider effect. In our study, this occurs even in the absence of any effort to lead subjects in our experiment to identify with their in-groups any more than Outsiders. The difference between our Local Outsider treatment (in which in-group members have more contact with Outsiders) and our Remote Outsider treatment (in which they have little contact) is like what has been called "social distance" in studies like Hoffman et al. (1996) and Fiedler et al. (2011), and in such studies reduced social distance is associated with increased cooperation. This problem would only be exacerbated in settings of environmental conflict where group identities may be strong and salient and social distances between in-groups and Outsiders may be great.

Further, the distribution of returns within a group matters. When returns from the public project are heterogeneous, this pro-social restraint is less than it is when returns are uniform. Little restraint is shown by those who benefit most from the public project. In addition, we also see that Non-Stakeholders (those with normal returns from the common fund) in our Heterogeneous Returns treatments show less restraint in the presence of negative externalities than do subjects in the Homogeneous Returns case-perhaps because they know they will soon be Stakeholder. The Heterogeneous Returns treatment also lets us confirm the importance of reciprocal action in this setting.

Our results show that in-group benefits from a public bad can lead to inefficient outcomes, that less social contact between the in-group and the injured parties causes more inefficiency, that favor-trading can reinforce and exacerbate these inefficient outcomes, and that 
the resulting social costs can be economically significant. Future research is needed to find institutions that encourage more restraint in the presence of harmful downstream externalities. 


\section{References}

Abbink, Klaus, Brandts, Jordi, Herrmann, Benedikt and Orzen, Henrik, 2010. "Intergroup Conflict and Intra-group Punishment in an Experimental Contest Game." American Economic Review, 100(1), 420-447.

Andreoni, James, 1995a. "Cooperation in Public-Goods Experiments: Kindness or Confusion?" American Economic Review, 85(4), 891-904.

Andreoni, James, 1995b. "Warm-Glow versus Cold-Prickle: The Effects of Positive and Negative Framing on Cooperation in Experiments." Quarterly Journal of Economics, 110(1), 1-21.

Baron, Jonathan, 2001. "Confusion of Group Interest and Self-Interest in Parochial Cooperation on Behalf of a Group." Journal of Conflict Resolution, 45(3), 283-296.

Bornstein, Gary, 2003. "Intergroup Conflict: Individual, Group, and Collective Interests." Personality and Social Psychology Review, 7(2), 129-145.

Bornstein, Gary and Ben-Yossef, Meyrav, 1994. "Cooperation in Intergroup and Single-Group Social Dilemmas." Journal of Experimental Social Psychology, 30(1), 52-67.

Burks, Stephen V., Carpenter, Jeffrey P. and Verhoogen, Eric, 2003. "Playing both roles in the trust game." Journal of Economic Behavior \& Organization, 51(2), 195-216.

Chaudhuri, Ananish, 2011. "Sustaining Cooperation in Laboratory Public Goods Experiments: A Selective Survey of the Literature." Experimental Economics, 14(1), 47-83.

Chen, Yan and Li, Sherry Xin, 2009. "Group Identity and Social Preferences." American Economic Review, 99(1), 431-457.

Cox, James C., Friedman, Daniel and Sadiraj, Vjollca, 2008. "Revealed Altruism." Econometrica, 76(1), 31-69.

Dawes, R M, 1980. "Social Dilemmas." Annual Review of Psychology, 31(1), 169-193.

Delaney, Jason and Jacobson, Sarah, 2013, "The Good of the Few: Reciprocity in the Provision of a Public Bad." Williams College Economics Department Working Papers. Williams College, Williamstown, MA.

Duflo, Esther and Pande, Rohini, 2007. "Dams." The Quarterly Journal of Economics, 122(2), 601-646.

Ellman, Matthew and Pezanis-Christou, Paul, 2010. "Organizational Structure, Communication, and Group Ethics." American Economic Review, 100(5), 2478-2491. 
Engel, Christoph, 2007. "How Much Collusion? A Meta-Analysis of Oligopoly Experiments." Journal of Competition Law and Economics, 3(4), 491-549.

Engel, Christoph and Rockenbach, Bettina, 2011. "We Are Not Alone: The Impact of Externalities on Public Good Provision." SSRN eLibrary.

Ferraro, Paul J., Rondeau, Daniel and Poe, Gregory L., 2003. "Detecting other-regarding behavior with virtual players." Journal of Economic Behavior \& Organization, 51(1), 99109.

Fiedler, Marina, Haruvy, Ernan and Li, Sherry Xin, 2011. "Social distance in a virtual world experiment." Games and Economic Behavior, 72(2), 400-426.

Fischbacher, Urs, 2007. "z-Tree: Zurich Toolbox for Ready-Made Economic Experiments." Experimental Economics, 10(2), 171-178.

Foley, Meghan, 2010, "Williamstown concerned about Pownal biomass plant." Bennington Banner. Media NewsGroup, Inc., Bennington, VT.

Gächter, Simon, 2007, Conditional cooperation: Behavioral regularities from the lab and the field and their policy implications. In: Bruno S. Frey and Alois Stutzer (Eds.), Economics and Psychology. A Promising New Cross-Disciplinary Field. CESifo Seminar Series. The MIT Press, Boston, MA.

Glöckner, Andreas, Irlenbusch, Bernd, Kube, Sebastian, Nicklisch, Andreas and Normann, HansTheo, 2011. "Leading with(out) Sacrifice? A Public-Goods Experiment with a Privileged Player." Economic Inquiry, 49(2), 591-597.

Goeree, Jacob K., Holt, Charles A. and Laury, Susan K., 2002. "Private Costs and Public Benefits: Unraveling the Effects of Altruism and Noisy Behavior." Journal of Public Economics, 83 2, 255-276.

Hoffman, Elizabeth, McCabe, Kevin and Smith, Vernon L, 1996. "Social distance and otherregarding behavior in dictator games." The American Economic Review, 86(3), 653-660.

Holland, Stephen P., Hughes, Jonathan E., Knittel, Christopher R. and Parker, Nathan C., 2013. "Some Inconvenient Truths About Climate Change Policy: The Distributional Impacts of Transportation Policies." National Bureau of Economic Research

Houser, Daniel and Kurzban, Robert, 2002. "Revisiting Kindness and Confusion in Public Goods Experiments." American Economic Review, 92(4), 1062-1069. 
Isaac, R. Mark, Norton, Douglas A. and Pevnitskaya, Svetlana, 2013. "Polarized Demands for Public Goods and the Generalized Voluntary Contributions Mechanism." Florida State University

Jacobson, Sarah and Petrie, Ragan, 2013. "Favor Trading in Public Good Provision." Experimental Economics, Forthcoming.

Jennings, Bill, 2012, "Voters will kill a peripheral canal." San Francisco Chronicle. Hearst Newspapers, San Francisco, CA, pp. A-18.

Ledyard, John O., 1995, Public goods: A survey of experimental research. In: John H. Kagel and Alvin E. Roth (Eds.), The Handbook of Experimental Economics. Princeton University Press, Princeton, NJ, USA.

Olson, Mancur, 1965, The logic of collective action: public goods and the theory of collective action. Harvard University Press, Cambridge, Mass.

Rabin, Matthew, 1993. "Incorporating Fairness into Game Theory and Economics." American Economic Review, 83(5), 1281-1302.

Reuben, Ernesto and Riedl, Arno, 2009. "Public Goods Provision and Sanctioning in Privileged Groups." Journal of Conflict Resolution, 53(1), 72-93.

Richter, Brian D., Postel, Sandra, Revenga, Carmen, Scudder, Thayer, Lehner, Bernhard et al., 2010. "Lost in development's shadow: The downstream human consequences of dams." Water Alternatives, 3(2), 14-42.

Schwartz-Shea, Peregrine, 1983. Normative rhetoric and the definition of cooperation. Dissertation Thesis, University of Oregon, Eugene, OR.

Schwartz-Shea, Peregrine and Simmons, Randy T., 1990. "The layered prisoners' dilemma: Ingroup versus macro-efficiency." Public Choice, 65(1), 61-83.

Schwartz-Shea, Peregrine and Simmons, Randy T., 1991. "Egoism, Parochialism, and Universalism." Rationality and Society, 3(1), 106-132.

Shitovitz, Benyamin and Spiegel, Menahem, 2003. "Cournot-Nash and Lindahl Equilibria in Pure Public 'Bad' Economies." Economic Theory, 22(1), 17-31.

Sobel, Joel, 2005. "Interdependent Preferences and Reciprocity." Journal of Economic Literature, 43(2), 392-436. 
Sonnemans, Joep, Schram, Arthur and Offerman, Theo, 1998. "Public Good Provision and Public Bad Prevention: The Effect of Framing." Journal of Economic Behavior \& Organization, 34(1), 143-161.

Wilson, Bart J., 2008. "Language games of reciprocity." Journal of Economic Behavior \& Organization, 68(2), 365-377.

Winwong, Kornpan, 2008, "Thailand: Water diversion plans lead to trouble - activists." Imaging Our Mekong (newsmekong.org), Bangkok, Thaliand. 


\section{Figures and Tables}

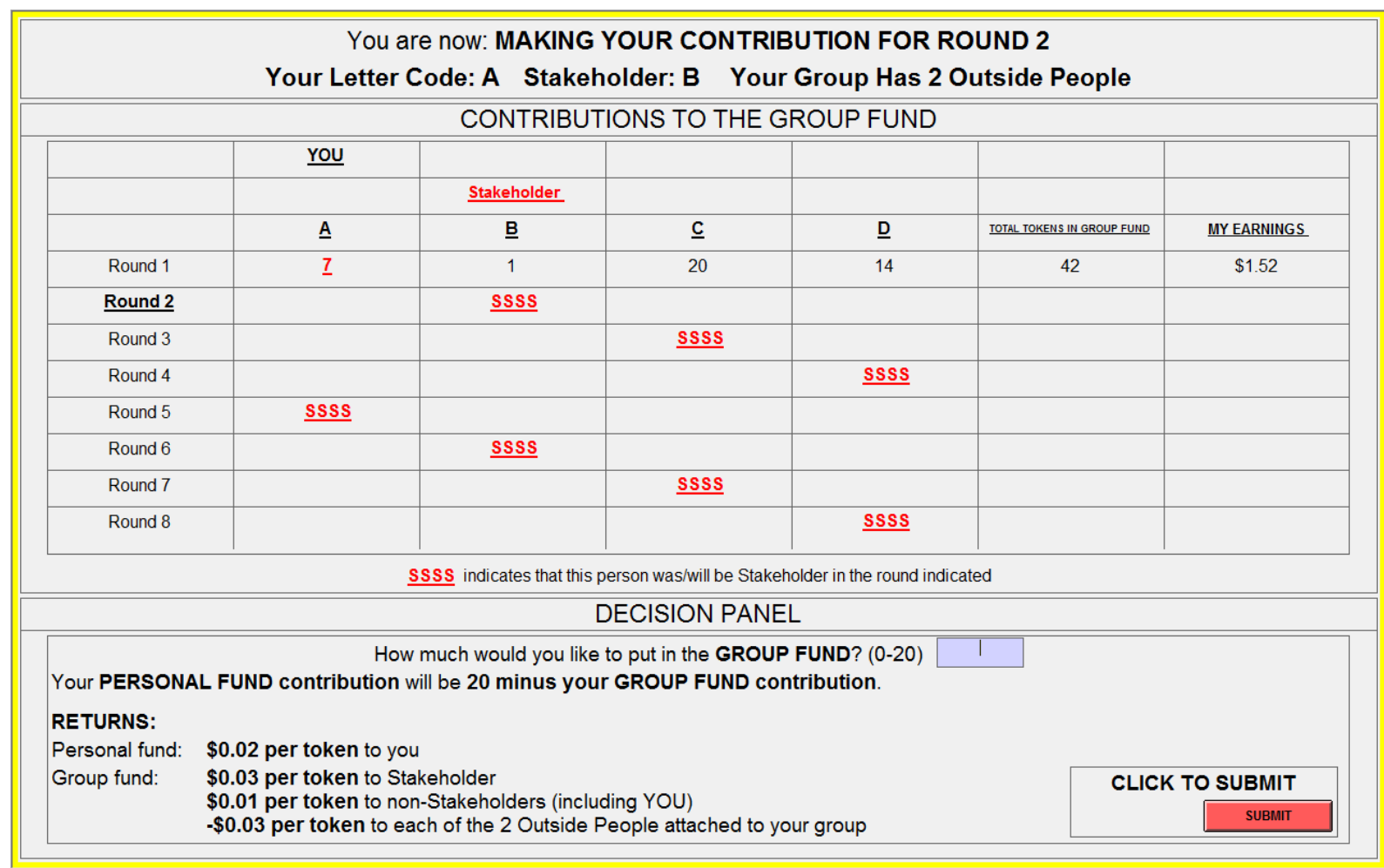

Figure 1: Heterogeneous Return Treatment with Outsiders Decision Screen 


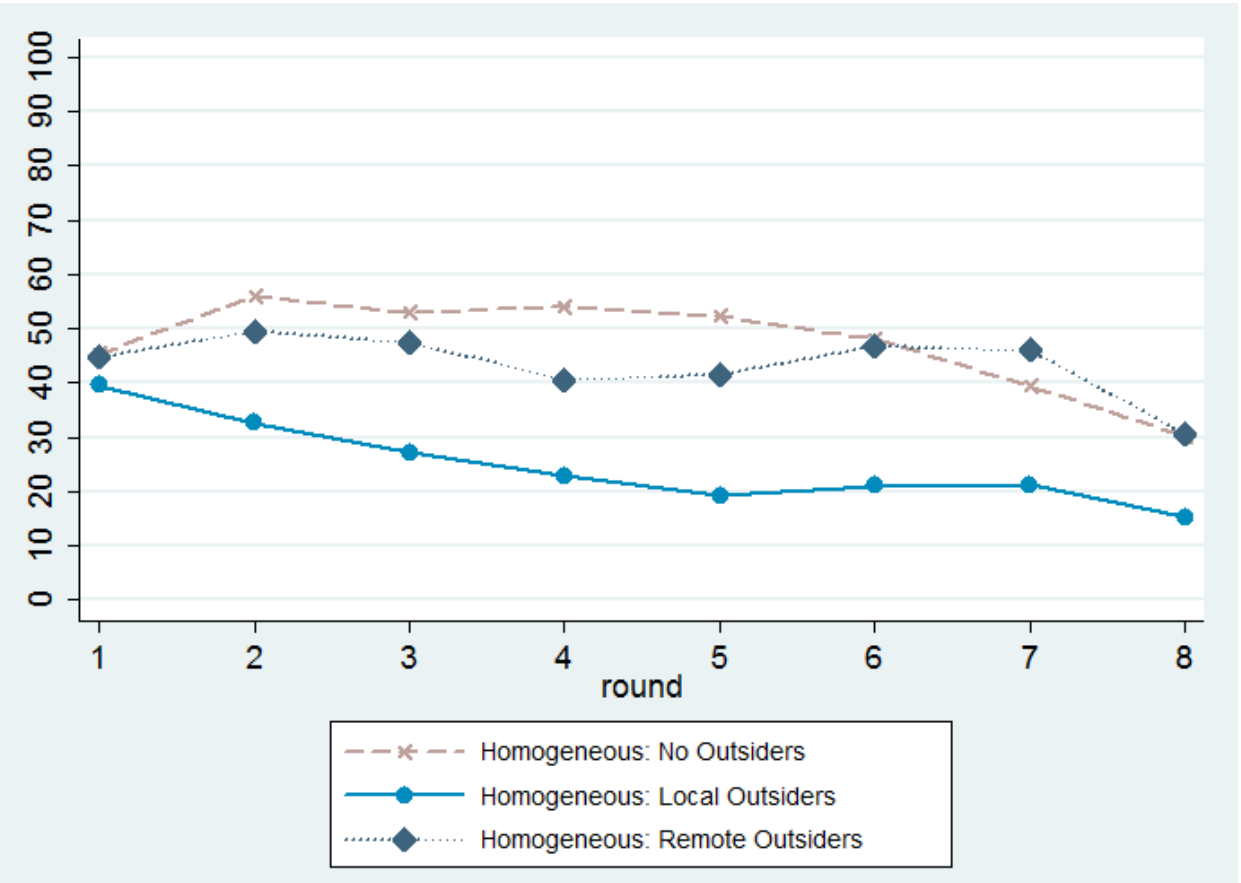

Figure 2a: Common Fund Contributions (in Percent of Endowment), Homogeneous Returns Treatment

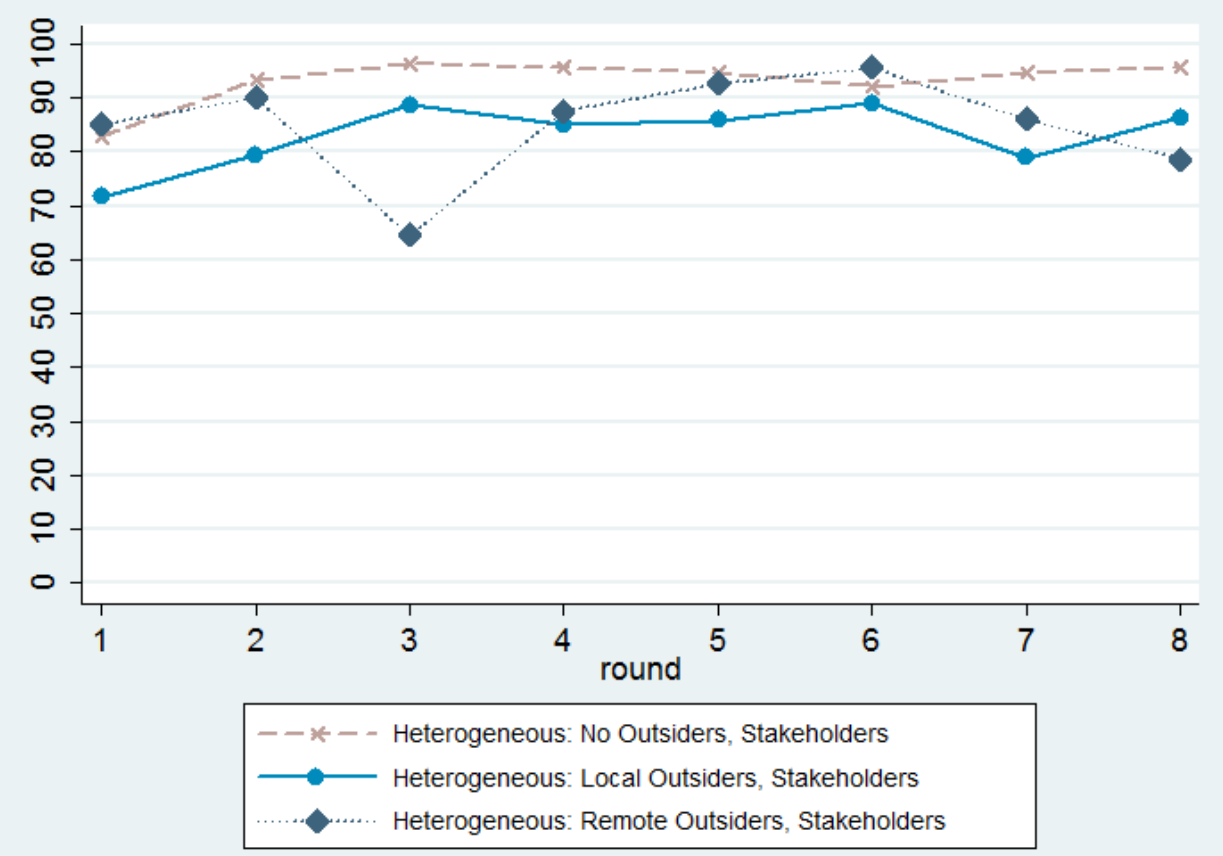

Figure 2b: Common Fund Contributions (in Percent of Endowment), Heterogeneous Returns Treatment, Stakeholders 


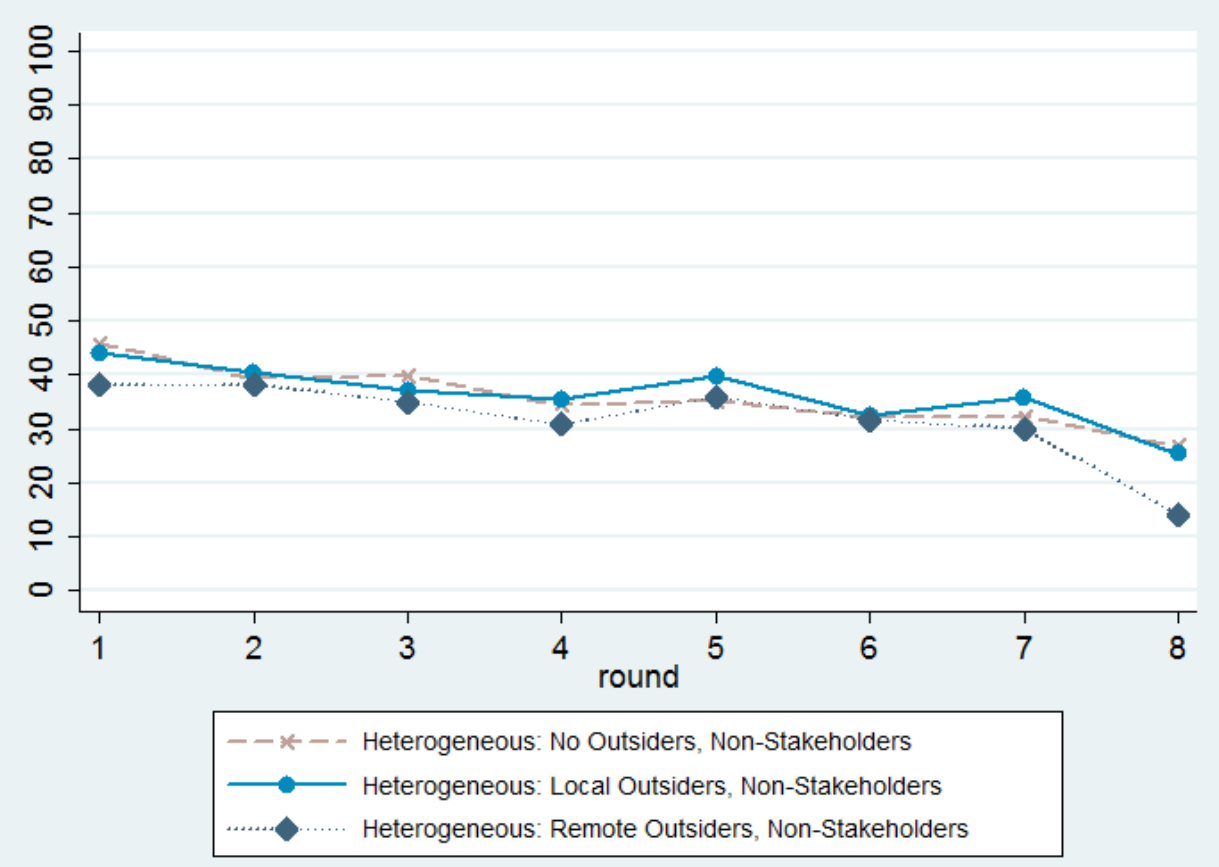

Figure 2c: Common Fund Contributions (in Percent of Endowment), Heterogeneous Returns Treatment, Non-Stakeholders 
Table 1: Common Fund Contributions by Treatment and Role (in Percent of Endowment)

\begin{tabular}{lccc}
\hline & $\begin{array}{c}\text { Homogeneous } \\
\text { Return }\end{array}$ & $\begin{array}{c}\text { Heterogeneous } \\
\text { Return Stakeholders }\end{array}$ & $\begin{array}{c}\text { Heterogeneous Return } \\
\text { Non-Stakeholders }\end{array}$ \\
\hline No-Outsider treatment & 47.297 & 93.125 & 35.733 \\
& $(22.180)$ & $(8.362)$ & $(17.127)$ \\
& $N=30$ & $N=29$ & $N=29$ \\
Local Outsider treatment & 24.914 & 83.092 & 36.294 \\
& $(16.207)$ & $(15.542)$ & $(18.602)$ \\
& $N=20$ & $N=19$ & $N=19$ \\
Remote Outsider treatment & 43.391 & 84.938 & 31.708 \\
& $(14.228)$ & $(18.401)$ & $(13.433)$ \\
& $N=10$ & $N=10$ & $N=10$ \\
\hline No-Outsider v. Local & & & 48 \\
$N$ & 50 & 48 & 0.899 \\
Wilcoxon rank-sum $p$ value & 0.001 & 0.018 & 39 \\
\hline No-Outsider v. Remote & & & 0.596 \\
$N$ & 40 & 39 & 29 \\
Wilcoxon rank-sum $p$ value & 0.673 & 0.284 & 0.614 \\
\hline Local v. Remote & & 29 & \\
$N$ & 30 & 0.580 & \\
Wilcoxon rank-sum $p$ value & 0.014 & & \\
\hline Standard deviations in parentheses. Unit of 0 obervation is a group & & \\
\hline
\end{tabular}

Standard deviations in parentheses. Unit of observation is a group. 
Table 2: OLS Regression of Average Group Contribution on Treatment Dummies

\begin{tabular}{lc}
\hline & I \\
\hline Local Outsider dummy & $-22.383^{* * * *}$ \\
& $(4.026)$ \\
Remote Outsider dummy & -3.906 \\
& $(2.940)$ \\
Heterogeneous Return Treatment dummy & $-11.564^{* *}$ \\
& $(4.629)$ \\
Local Outsider x Heterogeneous interaction & $22.944^{* * *}$ \\
& $(5.776)$ \\
Remote Outsider x Heterogeneous interaction & -0.118 \\
& $(4.716)$ \\
\hline Observations (groups) & 118 \\
$F$ & 8.10 \\
$R^{2}$ & 0.1550 \\
\hline
\end{tabular}

Standard errors (clustered on session) in parentheses. Unit of observation is a group. Dependent variable is the group's average contributions across all rounds of treatment. For Heterogeneous Return treatment, only NonStakeholder contributions are included.

Significance levels: *: $10 \%, * *: 5 \% * * *: 1 \%$ 
Table 3: Evidence of Reciprocity (Non-Stakeholder Contributions in Percent of Endowment)

\begin{tabular}{lccc}
\hline & $\begin{array}{c}\text { No-Outsider } \\
\text { treatment }\end{array}$ & $\begin{array}{c}\text { Local Outsider } \\
\text { treatment }\end{array}$ & $\begin{array}{c}\text { Remote Outsider } \\
\text { treatment }\end{array}$ \\
\hline How much do I give when current & 40.440 & 41.201 & 36.952 \\
Stakeholder was previously nice to me? & $(29.654)$ & $(35.143)$ & $(28.775)$ \\
How much do I give when current & 35.710 & 29.039 & 29.594 \\
Stakeholder was previously mean to me? & $(43.739)$ & $(27.941)$ & $(32.421)$ \\
\hline$N$ & 108 & 68 & 38 \\
Paired Wilcoxon signed-rank test $p$-value & 0.006 & 0.003 & 0.060 \\
\hline
\end{tabular}

Standard deviations in parentheses. Unit of observation is a subject. Threshold defined as average of all previous non-Stakeholder contributions of others in group (excluding self and current Stakeholder). "Previously nice" means current Stakeholder gave at or above this threshold when this subject was Stakeholder; "previously mean" means current Stakeholder gave below this threshold when this subject was Stakeholder. $N<$ relevant maximum number of subjects because some subjects did not face both a nice and mean Stakeholder by these definitions. 
Table 4. Panel Regression of Non-Stakeholder Contributions on History

\begin{tabular}{|c|c|c|c|c|}
\hline & $1(\mathrm{FE})$ & $2(\mathrm{FE})$ & $3(\mathrm{RE})$ & $4(\mathrm{RE})$ \\
\hline $\begin{array}{l}\text { Stakeholder average past } \\
\text { contributions to me }\end{array}$ & $\begin{array}{c}1.010 * * * \\
(0.256)\end{array}$ & $\begin{array}{c}0.912 * * * \\
(0.196)\end{array}$ & $\begin{array}{c}1.086 * * * \\
(0.249)\end{array}$ & $\begin{array}{c}0.913 * * * \\
(0.191)\end{array}$ \\
\hline $\begin{array}{l}\text { Average past Non-Stakeholder } \\
\text { contributions (excluding self) }\end{array}$ & $\begin{array}{c}0.126 \\
(0.102)\end{array}$ & $\begin{array}{l}0.122^{*} \\
(0.071\end{array}$ & $\begin{array}{c}0.177 * * * \\
(0.047)\end{array}$ & $\begin{array}{c}0.166 * * * \\
(0.032)\end{array}$ \\
\hline Period & $\begin{array}{c}-2.011 * * * * \\
(0.678)\end{array}$ & $\begin{array}{l}-2.356^{* * *} \\
(0.491)\end{array}$ & $\begin{array}{c}-1.955^{* * *} \\
(0.681)\end{array}$ & $\begin{array}{c}-2.297 * * * \\
(0.491)\end{array}$ \\
\hline Local dummy & & & $\begin{array}{c}3.744 \\
(11.724)\end{array}$ & \\
\hline $\begin{array}{l}\text { Local dummy } \times \text { Stakeholder } \\
\text { average past contributions to me }\end{array}$ & $\begin{array}{l}-0.004 \\
(0.412)\end{array}$ & & $\begin{array}{l}-0.130 \\
(0.404)\end{array}$ & \\
\hline $\begin{array}{l}\text { Local dummy } \times \text { Average past } \\
\text { Non-Stakeholder contributions } \\
\text { (excluding self) }\end{array}$ & $\begin{array}{l}-0.009 \\
(0.166)\end{array}$ & & $\begin{array}{l}-0.002 \\
(0.070)\end{array}$ & \\
\hline Local dummy $\times$ Period & $\begin{array}{c}0.006 \\
(1.139)\end{array}$ & & $\begin{array}{l}-0.008 \\
(1.149)\end{array}$ & \\
\hline Remote dummy & & & $\begin{array}{l}22.419^{*} \\
12.877)\end{array}$ & \\
\hline $\begin{array}{l}\text { Remote dummy } \times \text { Stakeholder } \\
\text { average past contributions to me }\end{array}$ & $\begin{array}{l}-0.559 \\
(1.139)\end{array}$ & & $\begin{array}{l}-0.711 \\
(0.607)\end{array}$ & \\
\hline $\begin{array}{l}\text { Remote dummy } \times \text { Average past } \\
\text { Non-Stakeholder contributions } \\
\text { (excluding self) }\end{array}$ & $\begin{array}{c}0.039 \\
(0.180)\end{array}$ & & $\begin{array}{l}-0.051 \\
(0.094)\end{array}$ & \\
\hline Remote dummy $\times$ Period & $\begin{array}{l}-1.984 \\
(1.269)\end{array}$ & & $\begin{array}{l}-1.808 \\
(1.277)\end{array}$ & \\
\hline Observations (rounds) & 1044 & 1044 & 1044 & 1044 \\
\hline Number of subjects & $\begin{array}{c}232 \\
F=8.01\end{array}$ & $\begin{array}{c}232 \\
F=20.22\end{array}$ & $\begin{array}{c}232 \\
\chi^{2}=132.47\end{array}$ & $\begin{array}{c}232 \\
\chi^{2}=116.44\end{array}$ \\
\hline$R^{2}$ (overall) & 0.1314 & 0.1364 & 0.1463 & 0.1381 \\
\hline
\end{tabular}

Robust standard errors in parentheses; specifications 1 and 2 are individual fixed-effects models and specifications 3 and 4 are random-effects models.

Significance levels: *: $10 \%, * *: 5 \% * * *: 1 \%$ 